\title{
Overall Parameters Design and Optimization System for Gun and Bullet
}

\author{
Zhifang Wei and Fang Wang
}

\begin{abstract}
The choosing of overall parameters, in the conceptual design stage, has been shown decisive, for developing efficient and reliable final gun and bullet products. Aimed at the feature that multidisciplinary knowledge will be related in the overall parameters design process, and in order to meet the various design requirement and aim, a multidisciplinary design optimization system is proposed to automatically acquire the optimized overall design parameters in this paper. Based on the empirical methods of individual disciplines including mechanics, ballistics, dynamics, the analyzing procedures for each discipline are developed, the coupling relations between disciplines are analyzed, and the integral analytic and optimized model of overall parameters are presented, then an integrated multidisciplinary design optimization system is built through integrating each analyzing procedure as well as the optimization software iSIGHT. Taking the $7.62 \mathrm{~mm}$ semi-automatic gun and bullet system as a verification example, the gun's firing rate and the bullet's destination kinetic energy are obviously improved compared to the initial values, which proves the feasibility and effectiveness of the proposed integration system in overall parameter design and optimization for gun and bullet system.
\end{abstract}

Index Terms-Gun and bullet system, integration system, multidisciplinary design optimization, overall parameters.

\section{INTRODUCTION}

For small arms consisted of gun and bullet, namely, gun and bullet system, the conceptual design process is the first stage, and it is of great significance of a reasonable choice of overall parameters for improving the final performance of gun and bullet products, which including ballistic parameters, bore structure parameters, powder parameters and projectile structure parameters, etc. Currently, the overall parameters design is a complex process involving lots of knowledge related to multiple disciplines, including interior ballistics, exterior ballistics, terminal ballistics, dynamics and structural mechanics, all of which are either loosely or tightly coupled to each other, the traditional conceptual design method relying on design experiences and referring congener products, show more deficiencies for the optimal parameters, therefore the optimization design of overall parameters of gun and bullet system should be of great importance for improving the design quality and efficiency [1], [2] via multidisciplinary optimization method.

Advanced design idea and method such as virtual design, multidisciplinary optimization design, and integrated

Manuscript received July 2, 2016; revised November 15, 2016

Zhifang Wei is with College of Mechatronic Engineering, North University of China, Taiyuan 030051, China (e-mail: 1686573847@ qq.com).

Fang Wang is with Jiang Nan Industries Group Co., LTD, Xiang Tan 411207, China (e-mail: 844251285@qq.com). simulation [3]-[5] were adopted in overall design process of complicated weapon system in developed countries, which turned the traditional design manner, draw-manufacture-shoot, into multifield and multidisciplinary collaborative design, and meanwhile changed the optimization design application from a single subject to the multi-domain and multi-subject. For example, the optimal design of mars exploration was finished via multi- objective design optimization [6] in the USA jet propulsion laboratory; the optimization of design parameters of cargo ships was studied by Abramowski [7], in which a single-objective and a multi-objective optimization examples were presented; a multidisciplinary design optimization method for the conceptual design of hypersonic aircraft was explored by Yoshinori MATSUNO [8], with the design of the aircraft and its flight trajectory successfully optimized; and the preliminary aircraft design optimization was finished by Chaudhry [9] to obtain the optimized preliminary design of an aircraft, based on multidisciplinary design and optimization approach; design, performance evaluation and optimization of a UAV were finished by Spyridon G. Kontogiannis and John A. Ekaterinaris [10], in which further improvements of the aerodynamic efficiency of the full configuration were carried out through computational optimization; and a methodology and a computational environment to enable a Pareto frontier analysis for the preliminary design optimization of a wing/horizontal tail/fuselage aircraft configuration were provided by Franco Mastroddi and Stefania Gemma [11] via Integrated multidisciplinary Design Optimization.

The overall parameters design process of gun and bullet system is an iteration process of design, analysis, appreciation and redesign, this paper proposes an integrated design optimization software system, which is aimed at a preliminary automatic design of optimized overall parameters for gun and bullet.

\section{MULTIDISCIPLINARY ANALYSIS AND OPTIMIZATION MODEL OF OVERALL PARAMETERS}

\section{A. Multidisciplinary Integrated Analysis Model}

According as the professional criterion or mathematical model governing the system, it is decomposed into the basic disciplines including terminal ballistics, external ballistics, internal ballistics, automatic machine dynamics, recoil energy, barrel strength and locking-mechanism strength, used for simulating the multidisciplinary product performance decided by the overall parameters. By analyzing the coupling parameter relations between each discipline, the multidisciplinary integrated analytic model is achieved as 
shown in Fig. 1.

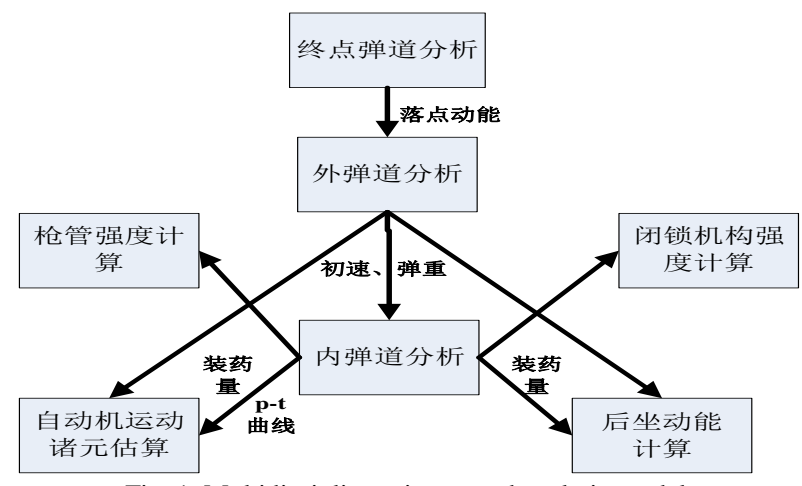

Fig. 1. Multidisciplinary integrated analytic model.

\section{B. Optimization Model}

The establishment of optimization model mainly includes defining design variables, specifying constraints, and creating objective functions.

\section{1) Objective function}

Objective function is the mathematical expression of certain desired performance characteristic expressed by design variables. For small arms, the power is always the most important criterion to estimate its performance, which relates to the damage effect to objectives, the firing rate, and the terminal spread. Accordingly, the bullet's kinetic energy at effective firing range and the gun's firing rate are selected as objective functions to estimate overall parameters in this paper.

The bullet's destination kinetic energy is given by:

$$
F_{1}(X)=E_{c}=\frac{1}{2} m v_{c}^{2}
$$

where, $m$ is warhead mass, and $v_{c}$ is warhead velocity at effective firing range.

And, the gun's firing rate is described as follows:

$$
F_{2}(X)=N=60 /\left(t_{h z}+t_{f j}+t_{y r}+t_{j f}+t_{0 d}\right)
$$

where, $t_{h z}$ is the back-moving time, $t_{f j}$ is the recoil time, $t_{y r}$ is the time for firing the primer, $t_{j f}$ is the hitting time, and $t_{0 d}$ is the time for the warhead from departure to pass through the gas-guide hole.

\section{2) Design variables}

Design variables should be those related to objective functions directly or indirectly, and having more influence to the objective functions. Thus, such parameters related to each discipline performance are selected as design variables in this model, as follows:

$$
X=\left[m, \omega, W_{0}, P_{m}, P_{j j}, S, \lambda, p_{1}, p_{2}, Q_{s}, Q\right]
$$

where, $m$ is warhead mass, $w$ is charge weight, $W_{0}$ is chamber volume inside projectile, $P_{m}$ is the maximum bore pressure, $P_{j j}$ is the engraving pressure, $S$ is the cross sectional area of bore, $\lambda$ is the total working trip of automatic mechanism, $P_{1}$ is advance pressure of recoil spring, $P_{2}$ is the maximal pressure of recoil spring, $Q_{s}$ is mass of the piston and bolt box, and $Q$ is the total mass of recoil automatic machine.

\section{3) Constraints}

In the process of optimization, the values of design variables need to satisfy some geometric or performing constraints. In this model, to ensure desired performance of each discipline except terminal ballistic and automatic machine dynamics, such constraints are considered as recoil energy requirements, barrel strength requirements, locking mechanism strength.

where

Recoil kinetic energy constraint is given by:

$$
\frac{1}{2} m v_{0}^{2}-E \leq 0
$$

Here, $v_{0}$ is warheads' initial velocity at the gunpoint, and $E$ is the maximum recoil kinetic energy.

And, locking mechanism strength constraint is defined as:

$$
\sigma_{b s \max }-[\sigma] \leq 0
$$

Here, $\sigma_{b s \max }$ stands for the maximum stress bore by the locking mechanism, and $[\sigma]$ the allowable stress.

In addition, barrel strength constraint is described as:

$$
p_{s}-p^{*} n \geq 0
$$

Here, $p_{s}$ is the maximum allowable pressure of barrel, $p$ is the bore pressure, and $n$ is the safety factor.

\section{OVERALl PARAMETERS DESIGN AND OPTIMIZATION SYSTEM FOR GUN AND BULLET}

\section{A. Analysis Procedure of Each Discipline}

Aiming at the disciplines related above, based on the theory of each discipline, the analysis model is created, and the corresponding calculation procedure is developed, including exterior ballistic design and calculation procedure, interior ballistic design and calculation procedure, automation movement data calculation procedure, barrel strength calculation procedure, locking mechanism strength calculation software and etc.

\section{1) Exterior ballistic calculation}

The velocity, displacement, altitude and inclination angle of the warhead is obtained at any time moving to the target, by solving the exterior ballistic equations as follows:

$$
\left\{\begin{array}{l}
\frac{d v}{d t}=-c H(y) F(v)-g \sin \theta \\
\frac{d \theta}{d t}=-\frac{g \cos \theta}{v} \\
\frac{d x}{d t}=v \cos \theta \\
\frac{d y}{d t}=v \sin \theta \\
\frac{d P}{d t}=-\rho g v \sin \theta
\end{array}\right.
$$

Here, $v$ is the moving velocity of the warhead, $\theta$ is the ballistic inclination angle, $x$ is the $x$-coordinate of the warhead centroid and $y$ the $y$-coordinate, and $p$ is air pressure, $\rho$ is air density.

\section{2) Interior ballistic calculation}

The velocity, displacement of the warhead and the bore 
pressure is got in the interior ballistic process, by solving the interior ballistic equations as follows:

$$
\left\{\begin{array}{l}
\psi_{i}= \begin{cases}\chi_{i} Z_{i}\left(1+\lambda_{i} Z_{i}+\mu_{i} Z_{i}^{2}\right) & \begin{cases}\chi_{i} Z_{i}\left(1+\lambda_{i} Z_{i}+\mu_{i} Z_{i}^{2}\right) & Z_{0} \leq Z_{i}<1 \\
\chi_{s i} Z_{i}\left(1+\lambda_{s i} Z_{i}\right) & 1 \leq Z_{i}<Z_{k i} \\
1 & Z=Z_{k i}\end{cases} \end{cases} \\
\frac{d Z_{i}}{d \bar{t}}= \begin{cases}\sqrt{\frac{\theta}{2 B_{i}}} \bar{p}^{n_{i}} & \left(Z \geq Z_{k}\right) \\
\left\{\sqrt{\frac{\theta}{2 B_{i}}} p^{-n_{i}}\right. & \left(Z<Z_{k}\right) \\
0 & \frac{d \bar{l}}{d \bar{t}}=\bar{v}\end{cases} \\
\frac{d \bar{v}}{d \bar{t}}=\frac{\theta}{2} \bar{p} \\
\bar{p}\left(\bar{l}+\bar{l}_{\psi}\right)=\sum_{i=1}^{n} \frac{f_{i} \omega_{i}}{f_{1} \omega} \psi_{i}-\bar{v}^{2}
\end{array}\right.
$$

Here, $v$ is the moving velocity of the warhead, $l$ is the warhead displacement, $p$ is the bore pressure, $w$ is the powder mass, $\psi$ is the powder's relative burned mass, $Z$ is powder's relative burned thickness, $\chi$ and $\lambda$ and $\mu$ are powder shape coefficient, $f$ and $\theta$ are correlative parameters of powder burning performance.

\section{3) Automation movement data calculation}

Through automation movement data calculation as shown in Fig. 2, the automation's velocity at the end of powder gas effect, back-moving to the place, starting recoiling, and recoiling to the place are obtained, then the gun's firing rate is calculated.

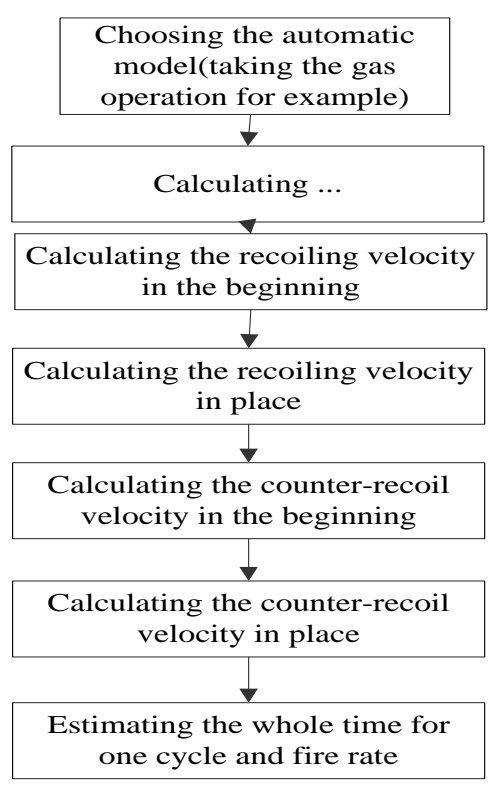

Fig. 2. Automation movement data calculation flow

\section{4) Barrel strength calculation}

In barrel outline design process, to get the reasonable wall thickness, strength calculation should be done at each main section of the barrel through the flow as shown in Fig. 3.

\section{5) Locking mechanism strength calculation}

With the interior ballistic parameters and locking mechanism structure parameters, the structure strength is calculated through the flow as shown in Fig. 4.

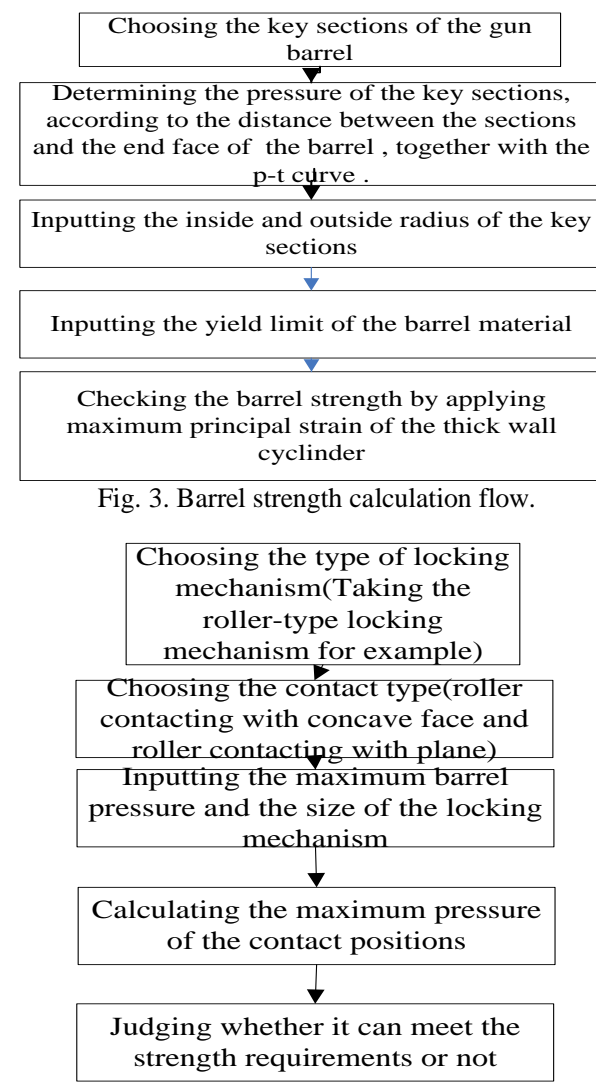

Fig. 4. Locking mechanism strength calculation flow.

\section{B. Overall Parameters Design and Optimization Software} System

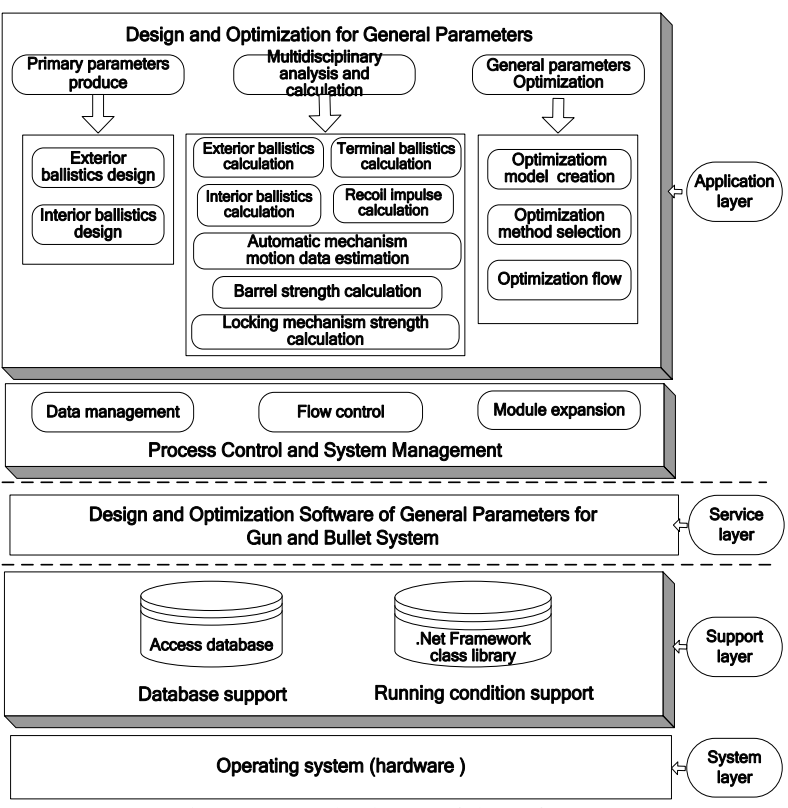

Fig. 5. General schema of the software

An overall parameters design and optimization software system is developed, to provided a practical, simple, efficient supporting environment for small arms designers to obtain the appropriate overall parameters, including such functional modules as overall parameters creating, multidisciplinary integrated analyzing and overall parameters optimizing. In which, individual calculating model and procedure of each discipline is packaged and integrated, and various design and 
process data are uniformly stored and managed based on database technology, and data extraction and transmission among various calculation programs is automatically realized by timely managing the input and output data of every calculation procedure, at the same time, the ISIGHT optimization software is integrated so that various types of optimization algorithms can be selected for optimization solution, consequently the software framework is achieved as shown in Fig. 5, and the software is developed with the main interface as shown in Fig. 6.

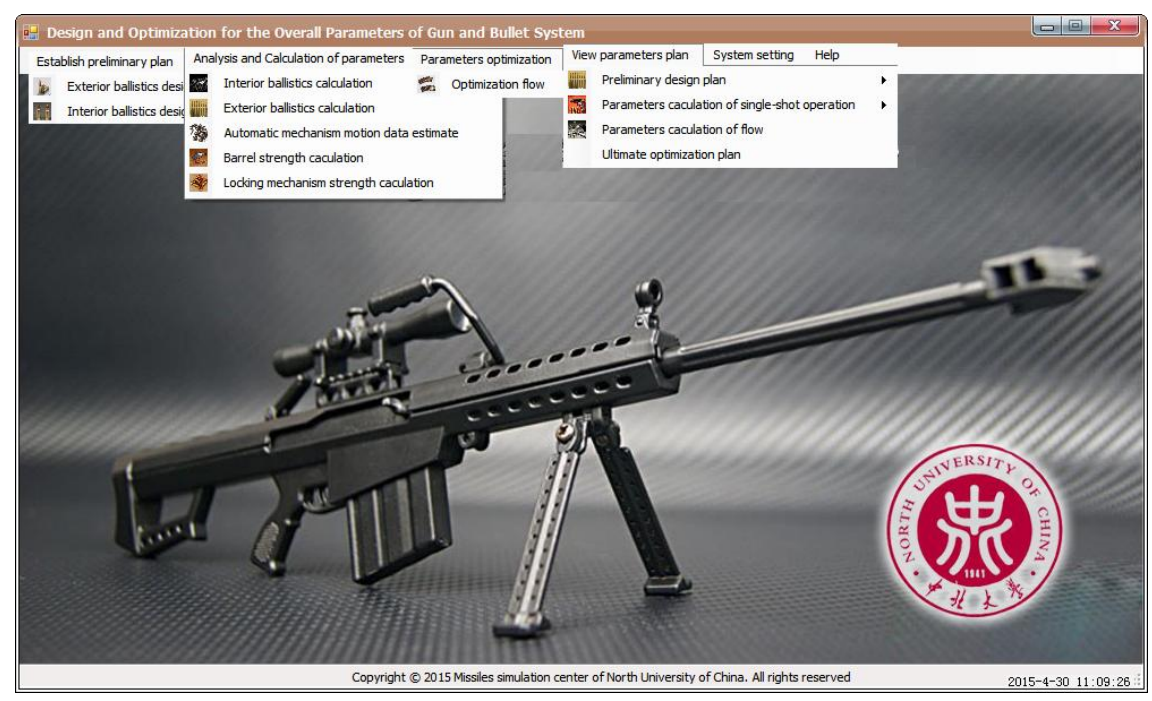

Fig. 6. Main interface of the software.

\section{Calculation Example}

Utilizing the software system presented in this paper, taking the $7.62 \mathrm{~mm}$ semi-automatic gun and bullet system as a test example, the multi-objective optimization of overall parameters is done to maximize the warhead's kinetic energy at effective firing range and the gun's firing rate, consequently the optimized parameters are obtained, with which the kinetic energy at effective range and the firing rate are improved by a certain degree Compared with the original design scheme.

\section{A. Overall Parameters Creating for Gun and Bullet}

The preliminary overall parameters of $7.62 \mathrm{~mm}$ semi-automatic gun and bullet system are created following the flow showed in Fig. 7, mainly including exterior ballistics design and interior ballistics design process.

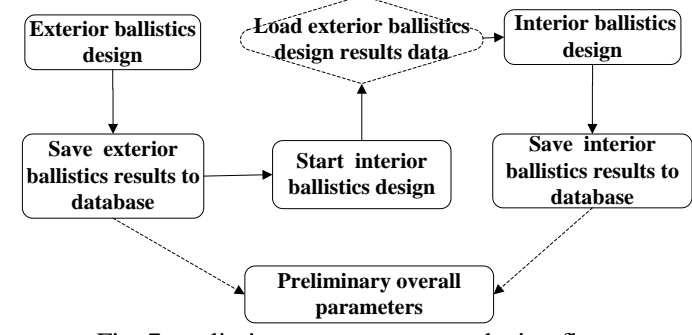

Fig. 7. preliminary parameters producing flow.

By running the above flow, external ballistics design procedure is firstly automatically carried out, to calculate the reasonable caliber, initial velocity and warheads mass, as the necessary inputs of interior ballistics design, gun and bullet design. The corresponding input parameters are taken as shown in Fig. 8, mainly including: recoil kinetic energy is less than $0.8 \mathrm{~kg} * \mathrm{~m}$, ballistic trajectory is low and flat, and objects wearing nylon vests protection should be effectively damaged at a distance of 400 meters, and so on. And many groups of initial velocity and warhead mass are consequently obtained, shown in Fig. 9.

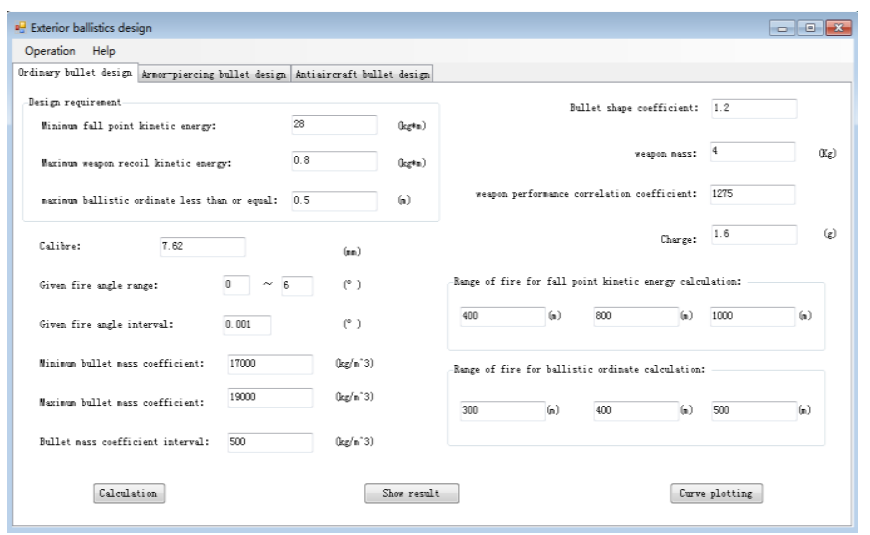

Fig. 8. Input interface of exterior ballistics design procedure.

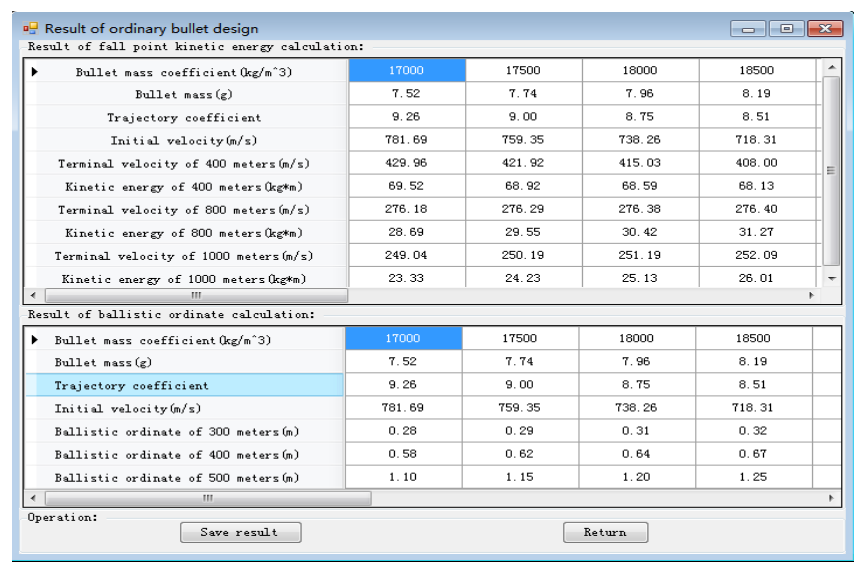

Fig. 9. Exterior ballistics design results.

With the external ballistics design results, namely, the initial velocity and warhead mass, interior ballistics design is then finished through the flow, to obtain the reasonable loading parameters and bore structure data, in which the initial inputs are defined as: chamber magnification coefficient is 1.68 , bore cross-sectional area is $47.6 \mathrm{~mm}^{2}$, 
minor power factor is 1.15 , charging density is from 820 $\mathrm{kg} / \mathrm{m}^{3}$ to $900 \mathrm{~kg} / \mathrm{m}^{3}$, and jamming pressure is $30 \mathrm{MPa}$, as shown in Fig. 10, and the computing results in Fig. 11.

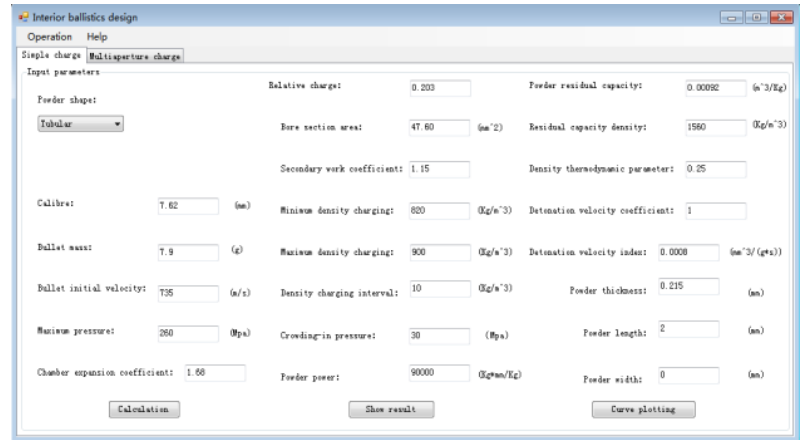

Fig. 10. Input interface of interior ballistics design procedure.

\begin{tabular}{|c|c|c|c|c|c|}
\hline \multicolumn{5}{|c|}{$\begin{array}{l}\text { Result of simple charge } \\
\text { Result t }\end{array}$} & 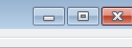 \\
\hline & $\begin{array}{l}\text { Chanber } \\
\text { capacity (mm'3) }\end{array}$ & $\begin{array}{l}\text { Bullet } \\
\text { stroke (ma) }\end{array}$ & $\begin{array}{l}\text { Chanber } \\
\text { length }(\mathrm{mm})\end{array}$ & $\begin{array}{l}\text { Barrel total } \\
\text { length (mom) }\end{array}$ & \begin{tabular}{l|l} 
Maximum \\
pressure (Mpa)
\end{tabular} \\
\hline \multirow{9}{*}{ 1 $\begin{array}{l}\Delta=8 \\
\Delta=8 \\
\Delta=8 \\
\Delta=8 \\
\Delta=8 \\
\Delta=8 \\
\Delta=8 \\
\Delta=8 \\
\Delta=8\end{array}$} & 1955.73 & 655.59 & 24. 46 & 680.05 & 254.38 \\
\hline & 1932.17 & 639.20 & 24.16 & 663.36 & 260.75 \\
\hline & 1909. 17 & 622.75 & 23.87 & 646.63 & 267.33 \\
\hline & 1886.71 & 600.77 & 23.59 & 630.37 & 274.14 \\
\hline & 1864.77 & 590.99 & 23.32 & 614.31 & 281.19 \\
\hline & 1843.33 & 575.38 & 23.05 & 598.44 & 288.48 \\
\hline & 1822.39 & 559.96 & 22.79 & 582.75 & 296.05 \\
\hline & 1801. 91 & 544.71 & 22.53 & 567.24 & 303.89 \\
\hline & 1781. 89 & 529.86 & 22.28 & 552.15 & 312.03 \\
\hline \multicolumn{6}{|l|}{ Operation } \\
\hline & \multicolumn{2}{|c|}{\begin{tabular}{|l|} 
Save result \\
\end{tabular}} & \multicolumn{3}{|c|}{ Return } \\
\hline
\end{tabular}

Fig. 11. Interior ballistics design results.

Consequently, by automatically running the above flow, overall parameters are elementally generated as follows:

$X_{0}=\left[m_{0}, \omega_{0}, W_{00}, P_{m 0}, P_{j j 0}, S_{0}, \lambda_{0}, p_{10}, p_{20}, Q_{s 0}, Q_{0}\right]$

$=[7.96,1.6,1947.85,264.63,30,47.6,140,61.74,108.78,0.61,0.84]$

The relevant symbols have the same meaning mentioned above.

\section{B. Multidisciplinary Integrated Analysis of Overall Parameters}

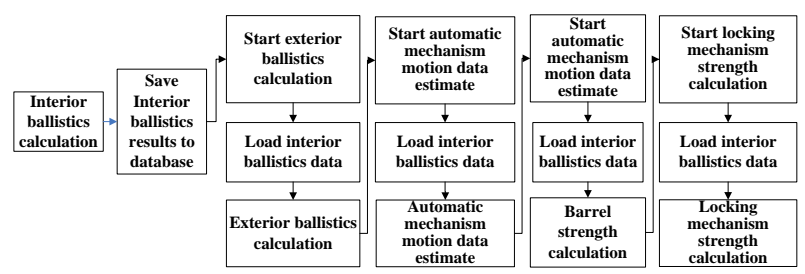

Fig. 12. multidisciplinary analysis flow.

Aimed at the preliminary parameters generated above, multidisciplinary analysis and calculation are completed following the flow shown in Fig. 12, to primitively estimate the performance of each discipline, mainly including interior ballistic calculation, exterior ballistics calculation, bullet,s kinetic energy calculation at the effective range, gun's recoil momentum calculation, motion data estimation for automatic mechanism, barrel strength calculation, and locking mechanism strength calculation.

In the process, all kinds of computing data are saved in a database by using unified object modeling techniques, data transferring between different calculating procedures is achieved using files analysis and reconstruction technology by analyzing inputs and outputs for each program, and database interface is developed to automatically introducing the corresponding parameters from the database to each calculating program.

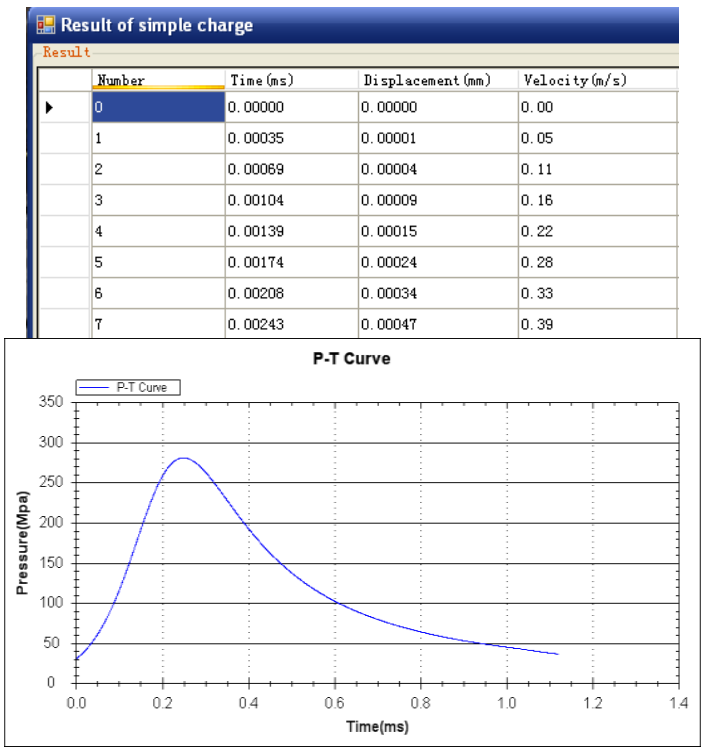

Fig. 13. Interior ballistics calculation results.

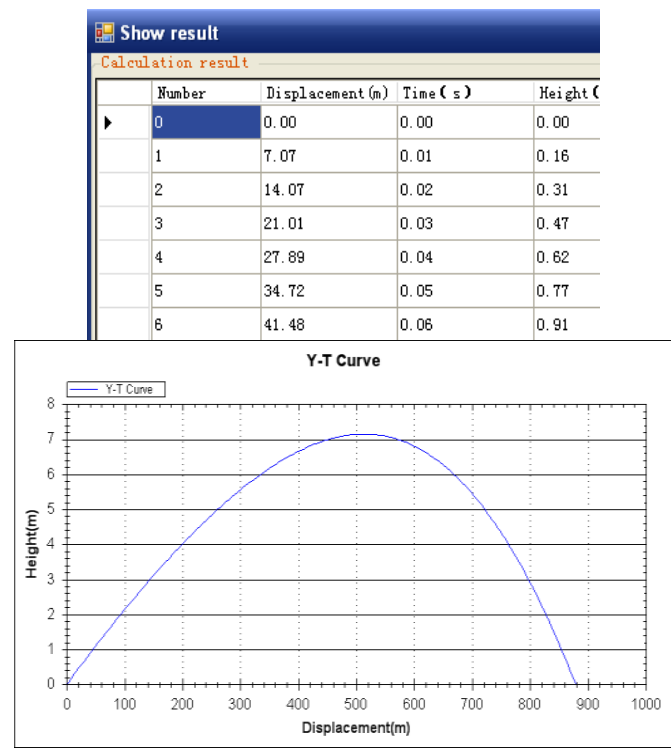

Fig. 14. Exterior ballistics calculation results.

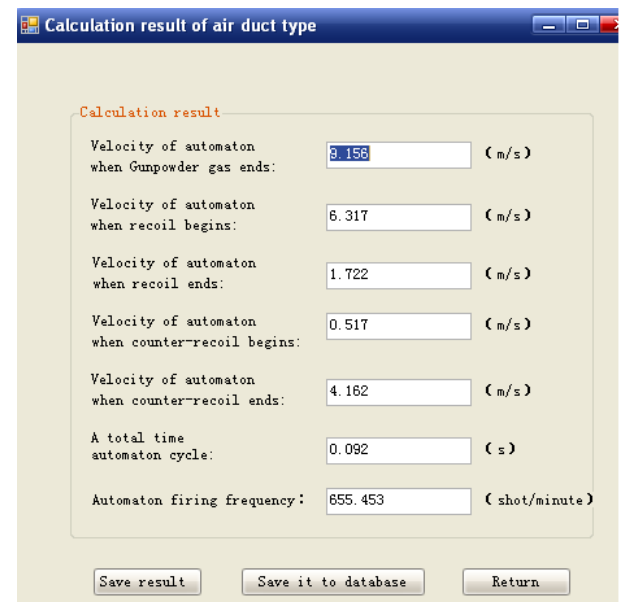

Fig. 15. Automatic mechanism motion data estimation results.

The corresponding calculation results are shown from Fig. 
13 to Fig. 17, where, interior ballistic calculation result is showed in Fig. 13, exterior ballistics calculation result in Fig. 14, automatic mechanism motion data estimating result in Fig. 15, barrel strength calculation result in Fig. 16, and locking mechanism strength calculation result is shown in Fig. 17.

\begin{tabular}{|l|l|l|}
$\begin{array}{l}\text { Pressure that } \\
\text { gun-barrel bear in } \\
\text { fact Ps (MPa) }\end{array}$ & $\begin{array}{l}\text { Chamber pressure } \\
\mathrm{P}(\mathrm{MPa})\end{array}$ & Assurance factor \\
\hline 202.840846195661 & 111.06711368581 & 1.82629078459231 \\
\hline 238.737366447125 & 162.029027894272 & 1.47342343251548 \\
\hline 276.363959570815 & 155.876304199757 & 1.77296966969817 \\
\hline 277.931543346554 & 148.144391356061 & 1.87608549201536 \\
\hline 271.412164472559 & 148.144391356061 & 1.8320785686731 \\
\hline 300.305575708038 & 143.486519269763 & 2.09291839565393 \\
\hline 271.956914924256 & 143.486519269763 & 1.89534819234804 \\
\hline 301.182165616461 & 139.289591398888 & 2.16227330837633 \\
\hline 318.538706379815 & 131.926095170483 & 2.41452387390213 \\
\hline 316.074372593675 & 113.403724014137 & 2.78716043358747 \\
\hline 291.589355214784 & 78.2991201361301 & 3.72404382971136 \\
\hline 285.523127500288 & 39.6451290087924 & 7.20197246519152 \\
\hline
\end{tabular}

Fig. 16. Barrel strength calculation results.

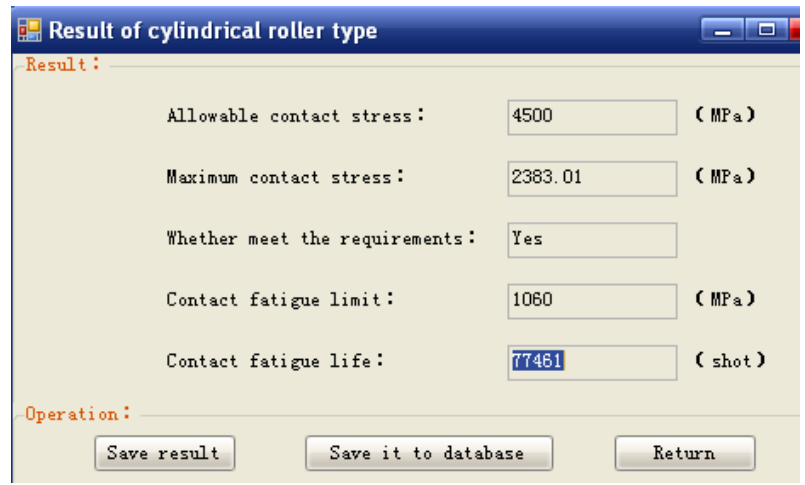

Fig. 17. Locking mechanism strength calculation results.

\section{Overall Parameters Optimization}

\section{1) Overall parameters optimization flow}

In order to obtain the optimized general parameters, the optimization flow is designed, shown in Fig. 18, in which Isight software is firstly called, secondly design variables are defined, constraints are described, and objective functions are established, then appropriate optimization algorithms are selected, finally the optimization results of parameters are obtained.

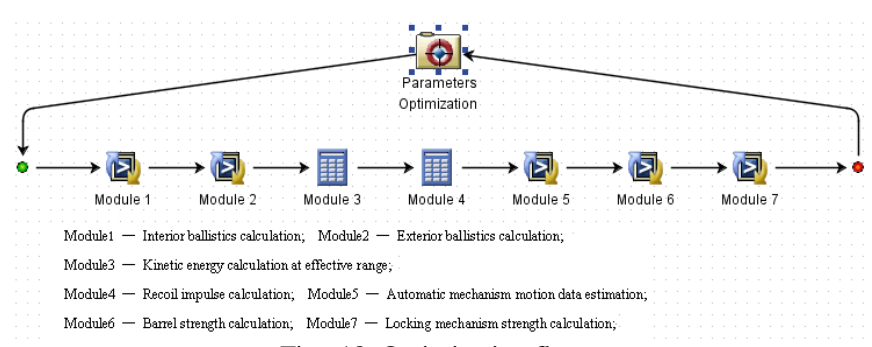

Fig. 18. Optimization flow.

\section{2) Optimization methods}

Optimization method is an important part of MDO technology, and is crucial to obtain the optimal solution of the optimization model. To solve the above optimization model, such optimization algorithms are selected in this paper as the second generation of non dominated sorting genetic algorithm (NSGA-II) [12], neighborhood cultivation of multi-objective genetic algorithm (NCGA), a global multi objective gradient search algorithm (PE) and other multi-objective optimization algorithms, because these algorithms have strong adaptability and flexibility to harmoniously treat each objective function, and with which such complicated multidisciplinary optimization problem can be successfully solved [13].

\section{3) Optimization results and analysis}

Respectively with three Optimization methods, NCGA, NSGA II, and AMGA, the optimization results are shown in Table I, compared with the previous scheme, better integration performance of small arms are achieved, that is to say, both the warhead's kinetic energy at effective firing range and the gun's firing rate are improved to some extent, meanwhile the largest ballistic height is lowered to a certain degree. From the comparison of the results, it is also observed that, higher efficiency will be achieved with NCGA and NSGA-II for multi-objective optimization when there are more design variables, and different results will be achieved with different optimization methods. Hence it is important to select appropriate optimization methods according to the special design demands.

TABLE I: OPTIMIZATION RESULTS COMPARISON

\begin{tabular}{|c|c|c|c|c|c|c|c|c|c|c|c|c|}
\hline $\begin{array}{l}\text { optimization } \\
\text { method }\end{array}$ & $\begin{array}{c}\text { Bullet } \\
\text { mass } \\
/ \mathrm{g}\end{array}$ & $\begin{array}{c}\text { Engraving } \\
\text { pressure } \\
/ \mathrm{MPa}\end{array}$ & $\begin{array}{c}\text { Bore } \\
\text { cross-sectional } \\
\text { area } / \mathrm{mm}^{2}\end{array}$ & $\begin{array}{c}\text { Iinitial } \\
\text { velocity } \\
/ \mathrm{m} / \mathrm{s}\end{array}$ & $\begin{array}{c}\text { Chamber } \\
\text { volume } \\
/ \mathrm{mm}^{3}\end{array}$ & $\begin{array}{c}\text { Charge } \\
\text { /g }\end{array}$ & $\begin{array}{c}\text { Maxim } \\
\text { um bore } \\
\text { pressure } \\
/ \mathrm{MPa}\end{array}$ & $\begin{array}{c}\text { Ballistic } \\
\text { height } \\
/ \mathrm{m}\end{array}$ & $\begin{array}{l}\text { Shooting } \\
\text { frequency } \\
/ 1 / \mathrm{min}\end{array}$ & $\begin{array}{c}\text { Recoil } \\
\text { momentum } \\
\text { /J }\end{array}$ & $\begin{array}{c}\text { Effective } \\
\text { range } \\
\text { momentum } \\
\text { /J }\end{array}$ & $\begin{array}{l}\text { Iteration } \\
\text { /number }\end{array}$ \\
\hline $\begin{array}{l}\text { Original } \\
\text { scheme }\end{array}$ & 7.9 & 30 & 47.6 & 735 & 1860 & 1.6 & 300 & 5.1 & 600 & 2180 & 310 & / \\
\hline NCGA & 7.76 & 26 & 47.85 & 751.62 & 1884 & 1.7 & 314.36 & 4.85 & 699.3 & 2191.8 & 303.1 & 1408 \\
\hline NSGAII & 7.83 & 31 & 47.44 & 748.82 & 1950 & 1.7 & 307.04 & 4.83 & 699.3 & 2195.5 & 307.19 & 1688 \\
\hline AMGA & 8.37 & 24 & 45.93 & 722.67 & 1917 & 1.64 & 309.88 & 4.82 & 687.2 & 2185.9 & 335.8 & 3508 \\
\hline
\end{tabular}

\section{CONCLUSIONS}

A study on the application of MDO method to the optimization of the overall parameters of small arms is presented, and an overall parameters design optimization software system for gun and bullet system is constructed.
Through the system, designers can achieve the automatic design, analysis and optimization of overall parameters of gun and bullet.

To demonstrate the validity of the software system proposed, $7.62 \mathrm{~mm}$ semi-automatic rifle system is taken as a 
verification example, the preliminary overall parameters are automatically produced, then multidisciplinary integrated analyzing are automatically completed to primitively estimate the general performance of the small arms, lastly, regarding the highest firing rate and the maximum kinetic energy within the effective firing range as the optimized objectives, and using the optimization arithmetic of NCGA, NSGA-II and so on, the overall parameters are optimized.

Hence, the proposed system seems a flexible multidisciplinary design environment for enhancing the preliminary design of overall parameters for gun and bullet, and with which, the overall parameters design efficiency should be effectively improved and the products' final performance should be also improved.

\section{REFERENCES}

[1] Z. R. Bogdanowicz, A. Tolano, K. Patel, and N. P. Coleman, "Optimization of weapon-target pairings based on kill probabilities," IEEE Transactions on Cybernetics, vol. 43, no. 6, pp. 1835-1844, 2013.

[2] W. Nan, L. C. Shen et al., "Robust optimization of aircraft weapon delivery trajectory using probability collectives and meta-modeling," Chinese Journal of Aeronautics, vol. 26, no. 2, pp. 423-434, 2013.

[3] R Kalavalapally, R Penmetsa, and R Grandhi, "Multidisciplinary optimization of a lightweight torpedo structure subjected to an underwater explosion," Finite Elements in Analysis and Design, vol. 43, no. 2, pp. 103-111, 2006.

[4] Y. K. Chang, "Multidisciplinary design optimization of earth observation satellite conceptual design using collaborative optimization," Journal of The Korean Society Aeronautical and Space Sciences, vol. 43, no. 6, pp. 568-583, 2015.

[5] T. David, J. J. Keane et al., "Multifidelity multidisciplinary whole-engine thermomechanical design optimization," Journal of Propulsion and Power, vol. 30, no. 6, pp. 1654-1666, 2014.

[6] R. D. Braun, H. S. Wright, and M. A. Croom, "Design of the ARES mars airplane and mission architecture," Journal of Spacecraft and Rockets, vol. 43, no. 5, pp. 1026-1034, 2006.

[7] A. Tomasz, "Methods to Preliminary Design Of Ships And Ship Performance Optimization," Naval Engineers Journal, vol. 125, no. 3, pp. 101-112, 2013.
[8] Y. Matsuno, T. Tsuchiya, S. Imamura, and H. Taguchi, "Multidisciplinary design optimization of long or short range hypersonic aircraft," Transactions of The Japan Society for Aeronautical And Space Sciences, vol. 57, no. 3, pp. 143-152, 2014.

[9] C. I. Ali and A. Ali, "Preliminary aircraft design optimization using genetic algorithms," Journal of Scientific \& Industrial Research, vol. 73, no. 5, pp. 302-307, 2014

[10] S. G. Kontogiannis and J. A. Ekaterinaris, "Design, performance evaluation and optimization of a UAV," Aerospace Science and Technology, vol. 29, no. 1, pp. 339-350, 2013.

[11] F. Mastroddi and S. Gemma, "Analysis of pareto frontiers for multidisciplinary design optimization of aircraft," Aerospace Science and Technology, vol. 28, no. 1, pp. 40-55, 2013.

[12] A. E. I. Brownlee and Jonathan A. Wright, "Constrained, mixed-integer and multi-objective optimisation of building designs by NSGA-II with fitness approximation," Applied Soft Computing, vol. 33, pp. 114-126, 2015

[13] K. Spiros, "Multi-objective optimization in spatial planning: Improving the effectiveness of multi-objective evolutionary algorithms (non-dominated sorting genetic algorithm II)," Engineering Optimization, vol. 47, no. 5, pp. 601-621, 2015.

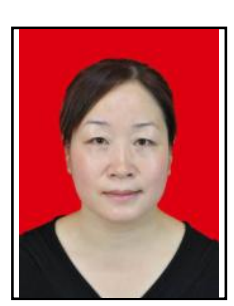

Zhifang Wei was born in China and obtained her $\mathrm{PhD}$ degree in artillery, automatic gun and ammunition engineering in North University of China in 2008. She joined the College of Mechatronic Engineering, North University of China in 1997 and now is an associate professor. Her research interests are focused on virtual design in arms engineering.

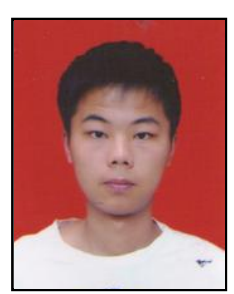

Fang Wang was born in China and obtained his master's degree in artillery, automatic gun and ammunition engineering in North University of China in 2014. His research interests are focused on simulation technology in arms engineering. 